\title{
Activation of peroxisome proliferator-activated receptor alpha in human peripheral blood mononuclear cells reveals an individual gene expression profile response
} Mark Bouwens ${ }^{1}$, Lydia A Afman ${ }^{* 1,2}$ and Michael Müller ${ }^{1,2}$

\author{
Address: ${ }^{1}$ Nutrition, Metabolism and Genomics Group, Division of Human Nutrition, Wageningen University, Bomenweg 2, 6703 HD \\ Wageningen, The Netherlands and ${ }^{2}$ Dutch Nutrigenomics Consortium, TI Food and Nutrition, Wageningen, The Netherlands \\ Email: Mark Bouwens - mark.bouwens@wur.nl; Lydia A Afman* - lydia.afman@wur.nl; Michael Müller - michael.muller@wur.nl \\ * Corresponding author
}

Published: 2 June 2008

BMC Genomics 2008, 9:262 doi:10.1 186/147|-2164-9-262
Received: 12 March 2008

Accepted: 2 June 2008

This article is available from: http://www.biomedcentral.com/I47I-2164/9/262

(c) 2008 Bouwens et al; licensee BioMed Central Ltd.

This is an Open Access article distributed under the terms of the Creative Commons Attribution License (http://creativecommons.org/licenses/by/2.0), which permits unrestricted use, distribution, and reproduction in any medium, provided the original work is properly cited.

\begin{abstract}
Background: Peripheral blood mononuclear cells (PBMCs) are relatively easily obtainable cells in humans. Gene expression profiles of PBMCs have been shown to reflect the pathological and physiological state of a person. Recently, we showed that the nuclear receptor peroxisome proliferator-activated receptor alpha (PPAR $\alpha$ ) has a functional role in human PBMCs during fasting. However, the extent of the role of PPAR $\alpha$ in human PBMCs remains unclear. In this study, we therefore performed gene expression profiling of PBMCs incubated with the specific PPAR $\alpha$ ligand WYI4,643.

Results: Incubation of PBMCs with WY 14,643 for 12 hours resulted in a differential expression of 1,373 of the 13,080 genes expressed in the PBMCs. Gene expression profiles showed a clear individual response to PPAR $\alpha$ activation between six healthy human blood donors. Pathway analysis showed that genes in fatty acid metabolism, primarily in $\beta$-oxidation were up-regulated upon activation of PPAR $\alpha$ with WYI4,643, and genes in several amino acid metabolism pathways were down-regulated.

Conclusion: This study shows that PPAR $\alpha$ in human PBMCs regulates fatty acid and amino acid metabolism. In addition, PBMC gene expression profiles show individual responses to WYI4,643 activation. We showed that PBMCs are a suitable model to study changes in PPAR $\alpha$ activation in healthy humans.
\end{abstract}

\section{Background}

The function of the nuclear receptor peroxisome proliferator-activated receptor alpha (PPAR $\alpha)$ has been studied extensively from the time of its discovery in the early 1990s [1]. PPAR $\alpha$ is a ligand activated nuclear receptor, which is known to be activated by free fatty acids and their derivatives [2,3]. Besides fatty acids, several synthetic compounds are available that specifically activate PPAR $\alpha$, including hypolipidemic drugs, such as fibrates and pirinixic acid (WY14,643) [4]. Synthetic PPAR $\alpha$ agonists mimic effects of dietary unsaturated fatty acids on hepatic gene expression in terms of regulation of target genes and molecular mechanism [5]. Activation of PPAR $\alpha$ with WY14,643 in mice showed that the main function of PPAR $\alpha$ in liver is the regulation of lipid metabolism, and more specifically fatty acid $\beta$-oxidation [6]. PPAR $\alpha$ was 
also found to be involved in regulation of amino acid metabolism [7] and inflammation [8,9]. In humans, the function of PPAR $\alpha$ is examined less thoroughly, because functional studies are more complicated. There is no human genetic disease linked to a dysfunctional PPAR $\alpha$ gene and tissue sampling is often not feasible in healthy volunteers. Blood is one of the few tissues which is readily available in healthy humans. Peripheral blood mononuclear cells (PBMCs) are relatively easily obtainable by isolation from blood. These cells consist of lymphocytes and monocytes/macrophages and it is known that PPAR $\alpha$ is expressed in these cells $[10,11]$. The use of PBMCs has proven to be highly robust in distinguishing a disease state from healthy state, by studying gene expression profiles of these cells $[12,13]$. Recently, we showed that PBMC gene expression profiles of healthy volunteers can also reflect changes between 24 and 48 hours fasting, when plasma fatty acid concentrations are elevated. In addition, we showed that PPAR $\alpha$ seems to have a functional role in human PBMC during fasting as several of the genes changed upon fasting were also changed upon incubation of PBMC with the specific PPAR a agonist WY14,643 [14]. However, the extent of the role of PPAR $\alpha$ in human PBMCs remains unclear. Therefore, we tried to elucidate the function of PPAR $\alpha$ in human PBMCs by whole genome microarray analysis of the PBMCs incubated with the specific PPAR $\alpha$ ligand WY14,643. Furthermore, to examine the complete role of PPAR $\alpha$ within PBMCs during fasting, we compared microarray analysis of PBMCs activated with WY14,643, with microarray analysis of PBMCs during 24 hours of fasting.

\section{Results \\ PPAR $\alpha$ regulation in PBMCs after incubation with WYI4,643}

Incubation of PBMC with the specific PPAR $\alpha$ ligand WY14,643 for 12 hours resulted in a differential expression of 1,373 of the 13,080 genes expressed in the PBMCs, indicating a PPAR $\alpha$-dependent regulation of $10.5 \%$ of the genes expressed in PBMC (Figure 1). More than half of these genes (56\%) were up-regulated. Pathway analysis of the genes changed upon activation of PPAR $\alpha$ with WY14,643, showed a marked increase in fatty acid metabolism, primarily in $\beta$-oxidation, and a decrease in several amino acid metabolism pathways (data not shown).

A peroxisome proliferator response elements (PPREs) was ascribed to 106 out of the 1,373 genes changed, using the study of Lemay et al [15]. Of these genes, 75 were up-regulated and 31 were down-regulated (Figure 2). Figure 2 shows the responses to activation of PPAR $\alpha$ for each person by illustrating the changes in gene expression of these 106 genes per individual. For several genes a clear variation in response upon PPAR $\alpha$ activation between individuals is present. Donor B and, especially, donor E show an

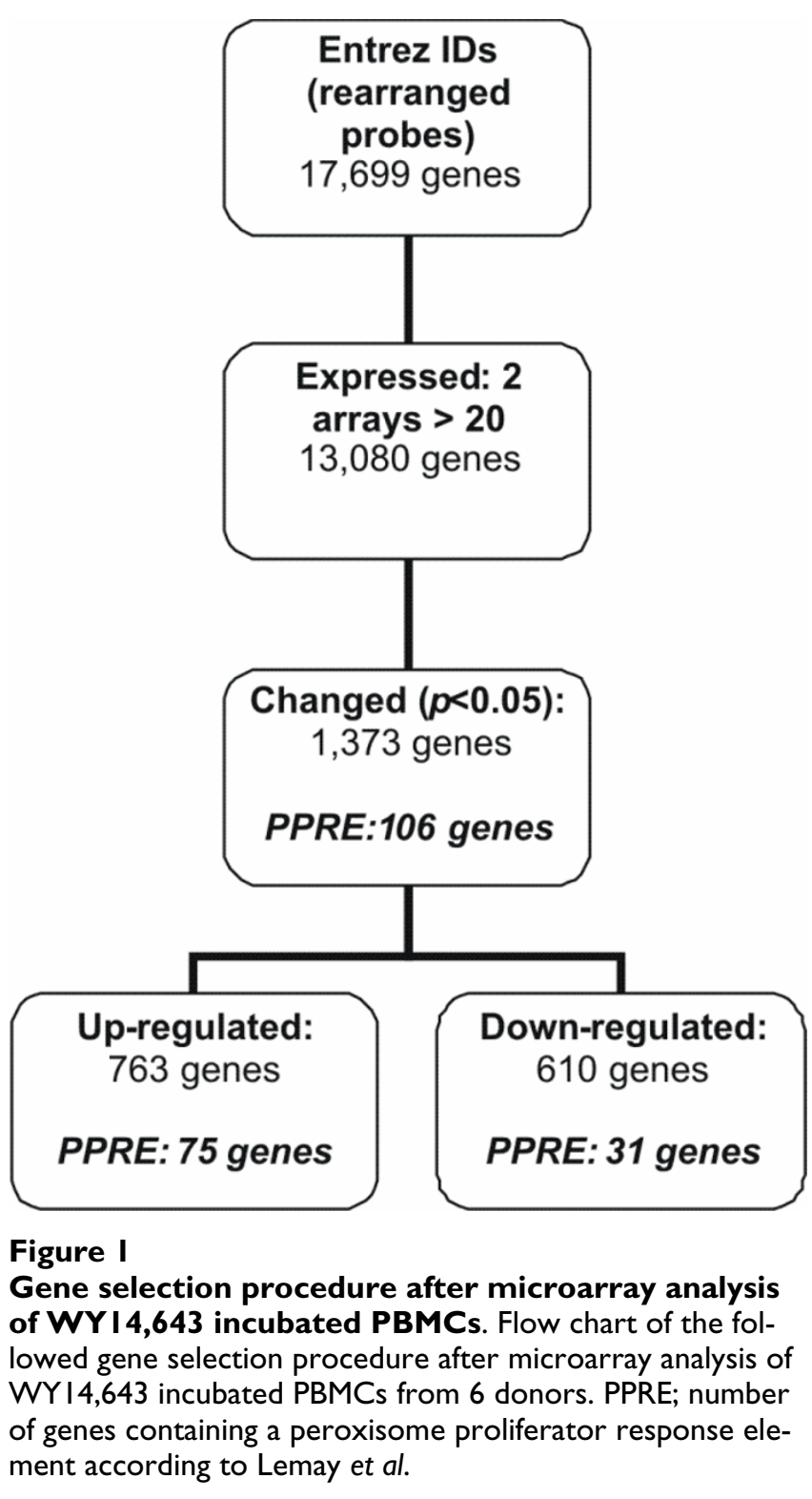

obvious distinction from the other donors. However, no difference could be found in the expression of PPAR $\alpha$ between the donors at basal level, and also after incubation with WY14,643 no change in expression of PPAR $\alpha$ was observed (data not shown). Another reason for the variation could be the difference in concentration of the PPAR $\alpha$ ligands, i.e. fatty acids, and other nutritional factors present in the blood during donation. Blood donors are commonly advised to eat before donating blood. To investigate whether the nutritional status influences changes in gene expression, we incubated PBMCs of four volunteers, obtained after a meal and after an overnight fast, with WY14,643. Using QPCR, we determined the changes in PBMC gene expression of genes that showed either a low (PDK4, SLC25A20, ACAA2) or a high varia- 


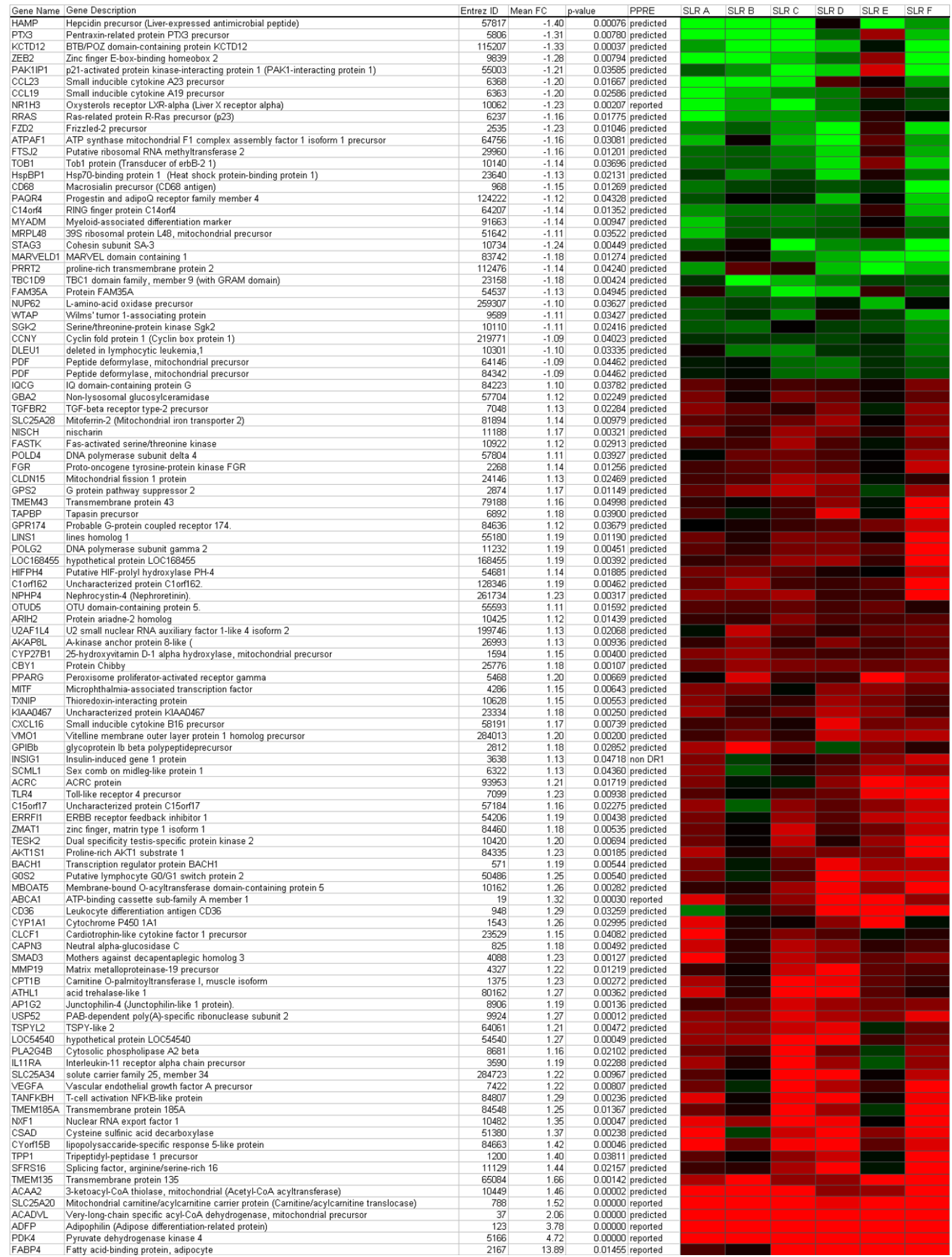

Figure 2

Genes changed after incubation with WY I4,643, containing a predicted or reported PPRE. Heatmap of the signal log ratio of genes changed upon incubation with WY 14,643 that contained a predicted or reported PPRE. Red indicates up-regulation compared to the vehicle incubated PBMCs and green indicates down-regulation. SL R, signal log ratio; PPRE, peroxisome proliferator response element 


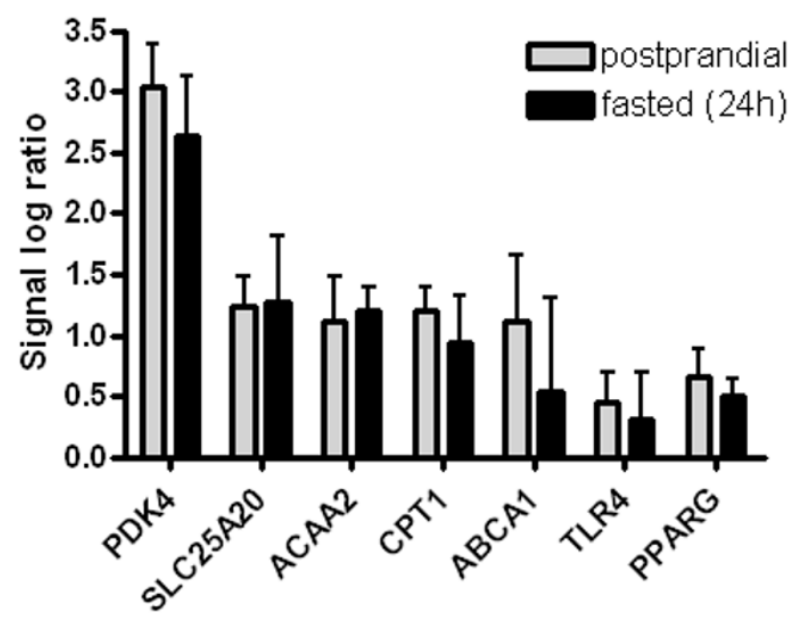

Figure 3

Gene expression changes of PBMCs incubated with WY | 4,643 isolated postprandial or after an overnight fast. Mean gene expression changes of PBMCs incubated with WY 14,643, isolated postprandial or after an overnight fast. Error bars indicate standard deviations. PDK4, Pyruvate dehydrogenase kinase 4; SLC25A20, carnitine-acylcarnitine translocase; ACAA2, acetyl-Coenzyme A acyltransferase 2; CPTI, Carnitine palmitoyltransferase I; ABCA I, ATP binding cassette transporter I; TLR4, Toll-like receptor-4; PPAR $\gamma$, peroxisome proliferator-activated receptor gamma.

tion (CPT1, ABCA1, TLR4, PPAR $\gamma$ ) between donors in the microarray analyzes of the first study (Figure 3 ). No significant differences were observed in gene expression between the fasted and postprandial state.

To analyze whether the genes that did not have a PPRE according to Lemay et al. might have other transcriptional binding sites, a network analysis and a subsequent transcription factor binding site search with Genomatix software was performed. The network analysis showed that, besides the transcription factor PPAR, the transcription factors NFkB, JUN, TP53, SP1 and CTNNB1 were also directly linked to at least 10 genes from the list of 1,373 genes, The subsequent search for binding sites resulted in an additional 122 genes that could be linked to a PPRE and revealed that another 371 genes could be linked to at least one of the other selected transcription factors (see Additional file 1).

To obtain a selection of robust responding genes upon activation of PPAR $\alpha$ with WY14.643, genes were selected that were more than $10 \%$ up or down regulated in all donors. This resulted in a list of 58 genes, including several known PPAR $\alpha$ target genes (ADFP, PDK4, SLC25A20) (Figure 4$)$, with a main function in fatty acid $\beta$-oxidation.
Remarkably, only $16 \%$ of the genes in this list contained a predicted or reported PPRE.

To validate our data observed with microarray analyzes a selection of genes changed in the microarray analyzes was also measured with quantitative real time PCR (Q-PCR). In concordance with our microarray results, Q-PCR analyzes resulted in similar changes in expression of all genes analyzed (Figure 5).

\section{PPAR $\alpha$ regulation in PBMCs during fasting}

Figure 6 shows the genes changed upon 24 hours fasting in healthy human volunteers with the number of genes that contain a PPRE. Comparison of gene expression profiles of PBMCs incubated with the PPAR $\alpha$ ligand WY14,643 and fasted for 24 hours resulted in an overlap of 238 genes, indicating that around $14 \%$ of the genes changed during fasting are regulated by PPAR $\alpha$ (Figure 7). Pathway analysis showed that these 238 genes were primarily involved in fatty acid metabolism. We found no overlap in pathways involved in amino acid metabolism. Exploration of the genes involved in fatty acid metabolism showed that fatty acid $\beta$-oxidation was specifically regulated, both in WY14,643 incubated cells and in PBMCs isolated after fasting (data not shown)

\section{Discussion}

In the present study, we showed that activation of the nuclear receptor PPAR $\alpha$ in peripheral blood mononuclear cells results in a considerable change in gene expression profiles, as $10.5 \%$ of the genes expressed exhibited altered gene expression levels after incubation with the specific PPAR $\alpha$ agonist WY14,643. The main function of PPAR $\alpha$ in PBMCs appeared to be the regulation of fatty acid $\beta$-oxidation and other lipid metabolism related functions, which is in line with results from mice studies in liver [16] and intestine [17], and human cell line studies [18,19]. Moreover, the observed down-regulation of amino acid metabolism has been shown before in liver in studies comparing wild type mice to the PPAR $\alpha$ knock out mouse model [7].

Besides the possible roles of PPAR $\alpha$ in PBMCs, this study also demonstrates strong individual variability between the subjects in gene expression responses to activation with WY14,643. It appears that each donor has its own specific gene expression profile response to PPAR $\alpha$ activation, which results in distinct differences in the expression of certain genes after WY14,643 incubation. Beck et al. also reported differences in responsiveness in gene expression between individuals, after incubation of endothelial cells with LPS. However, endothelial cell cultures were already divided beforehand into type I or type II responders based on their LPS mediated IL8 production [20]. In another study, incubation of cultured macrophages with 
oxidized low-density lipoprotein resulted in a person-specific inflammatory gene expression response that could be correlated to changes in gene expression of scavenger receptors [21]. However, we did not find a correlation between basal PPAR $\alpha$ expression or changes in PPAR $\alpha$ expression and the observed variation in gene expression changes. In addition, the differences observed are probably not caused by the nutritional status of the subjects at baseline, as we did not observe differences in expression changes of selected PPAR $\alpha$ target genes between the postprandial and the fasted state of PBMCs incubated with WY14,643. However, it should be noted here that only four subjects were studied. A reason for the difference in response of the donors in the first study could be genetic variation, such as single nucleotide polymorphisms (SNPs) in the PPAR $\alpha$ gene, its target genes or PPAR $\alpha$ cofactors involved in activation of gene transcription. Furthermore, epi-genetic variation such as methylation status

\begin{tabular}{|c|c|c|c|c|c|c|c|c|c|c|c|}
\hline Gene Name & Gene Description & Mean FC & $p$ value & Entrez ID & PPRE & SLR A & SLR B & SLR C & SLR D & SLR E & SLR F \\
\hline ADFP & Adipose differentiation-related protein & 3.78 & $2.86 \mathrm{E}-10$ & 123 & reported & & & & & & \\
\hline PDK4 & Pyruvate dehydrogenase kinase isozyme 4 & 4.72 & $6.16 \mathrm{E}-07$ & 5166 & reported & & & & & & \\
\hline ACADVL & Very-long-chain specific acyl-CoA dehydrogenase & 2.06 & 1.05E-07 & 37 & predicted & & & & & & \\
\hline LY6G5B & Casein kinase II subunit beta & 1.88 & $4.82 \mathrm{E}-05$ & 58496 & - & & & & & & \\
\hline LOC283874 & Hypothetical protein FLJ20393 & 1.66 & 8.72E-05 & 283874 & - & & & & & & \\
\hline SLC25A20 & Mitochondrial carnitine/acylcarnitine carrier protein & 1.52 & 8.68E-07 & 788 & reported & & & & & & \\
\hline IMPA2 & Inositol monophosphatase 2 & 1.47 & 1.01E-05 & 3613 & - & & & & & & \\
\hline C21 orf7 & TAK1-like protein. & 1.40 & 1.79E-04 & 56911 & - & & & & & & \\
\hline ST14 & Suppressor of tumorigenicity protein 14 & 1.60 & 2.84E-05 & 6768 & - & & & & & & \\
\hline HS3ST1 & Heparan sulfate glucosamine 3-0-sulfotransferase 1 & 1.51 & $2.55 \mathrm{E}-04$ & 9957 & - & & & & & & \\
\hline ETFDH & Electron transfer flavoprotein-ubiquinone oxidoreductase, mitochondrial & 1.42 & $1.32 \mathrm{E}-04$ & 2110 & - & & & & & & \\
\hline MICALL2 & MICAL-like protein 2 . & 1.36 & 1.65E-04 & 79778 & - & & & & & & \\
\hline MAP3KB & Mitogen-activated protein kinase kinase kinase 8 & 1.60 & 2.35E-04 & 1326 & - & & & & & & \\
\hline TMEM135 & Transmembrane protein 135 & 1.66 & $1.42 \mathrm{E}-03$ & 65084 & predicted & & & & & & \\
\hline ACAA2 & 3-ketoacyl-CoA thiolase, mitochondrial & 1.46 & 2.37E-05 & 10449 & predicted & & & & & & \\
\hline BZRAP1 & Peripheral-type benzodiazepine receptor-associated protein 1 & 1.36 & 2.93E-05 & 9256 & - & & & & & & \\
\hline $\mathrm{ABCC} 3$ & Canalicular multispecific organic anion transporter 2 & 1.34 & $9.88 \mathrm{E}-05$ & 8714 & - & & & & & & \\
\hline LOC158830 & similar to Ab2-183 & 1.41 & $1.51 \mathrm{E}-04$ & 158830 & - & & & & & & \\
\hline C20orf119 & Polyadenylate-binding protein 1-like. & 1.40 & 2.80E-04 & 80336 & - & & & & & & \\
\hline PPP1R3E & Homeobox and leucine zipper protein Homez & 1.31 & 1.29E-04 & 90673 & - & & & & & & \\
\hline PILRB & paired immunoglobulin-like type 2 receptor beta isoform $b$ & 1.32 & $1.58 \mathrm{E}-04$ & 29990 & - & & & & & & \\
\hline HBEGF & Heparin-binding EGF-like growth factor & 1.36 & 7.70E-05 & 1839 & - & & & & & & \\
\hline CXCL2 & Macrophage inflammatory protein 2-alpha & 1.31 & $6.44 \mathrm{E}-04$ & 2920 & - & & & & & & \\
\hline $\operatorname{CCDC} 17$ & coiled-coil domain containing 17 & 1.25 & 6.35E-04 & 149483 & - & & & & & & \\
\hline CYorf15B & lipopolysaccaride-specific response 5 -like protein & 1.42 & 4.61E-04 & 84663 & predicted & & & & & & \\
\hline NLRC4 & Caspase recruitment domain-containing protein 12 & 1.36 & $3.15 \mathrm{E}-04$ & 58484 & - & & & & & & \\
\hline USP52 & PAB-dependent poly(A)-specific ribonuclease subunit 2 & 1.27 & 1.17E-04 & 9924 & predicted & & & & & & \\
\hline FNBP4 & formin binding protein 4 & 1.29 & 3.83E-04 & 23360 & - & & & & & & \\
\hline COG3 & Conserved oligomeric Golgi complex component 3 & 1.23 & 6.07E-04 & 83548 & - & & & & & & \\
\hline CD300A & CMRF $35-\mathrm{H}$ antigen precursor & 1.26 & 5.91E-04 & 11314 & - & & & & & & \\
\hline $\mathrm{ABCC} 5$ & Multidrug resistance-associated protein 5 & 1.24 & 9.97E-04 & 10057 & - & & & & & & \\
\hline CREBZF & CREB/ATF bZIP transcription factor & 1.26 & $2.51 \mathrm{E}-03$ & 58487 & - & & & & & & \\
\hline MPP7 & palmitoylated membrane protein 7 & 1.24 & 8.44E-04 & 143098 & - & & & & & & \\
\hline $\mathrm{ECH} 1$ & Delta(3,5)-Delta(2,4)-dienoyl-CoA isomerase, mitochondrial & 1.23 & $1.38 \mathrm{E}-03$ & 1891 & - & & & & & & \\
\hline DEADC1 & deaminase domain containing 1 & 1.20 & 5.78E-04 & 134637 & - & & & & & & \\
\hline CLK2 & Dual specificity protein kinase CLK2 & 1.19 & $1.52 \mathrm{E}-03$ & 1196 & - & & & & & & \\
\hline TTRAP & TRAF and TNF receptor-associated protein & 1.23 & $1.15 \mathrm{E}-03$ & 51567 & - & & & & & & \\
\hline SPG7 & Paraplegin & 1.19 & 9.28E-04 & 6687 & - & & & & & & \\
\hline MTX3 & metaxin 3 & 1.14 & 5.25E-03 & 345778 & - & & & & & & \\
\hline CCDC130 & Coiled-coil domain-containing protein 130 & 1.20 & 1.18E-03 & 81576 & - & & & & & & \\
\hline CBY1 & Protein Chibby & 1.18 & 1.07E-03 & 25776 & predicted & & & & & & \\
\hline SYTL1 & Synaptotagmin-like protein 1 & 1.17 & 1.75E-03 & 84958 & - & & & & & & \\
\hline C6or70 & Uncharacterized protein C6orf70 & 1.17 & 2.19E-03 & 55780 & - & & & & & & \\
\hline GPNMB & Transmembrane glycoprotein NMB & -1.41 & 9.23E-06 & 10457 & - & & & & & & \\
\hline EMR1 & EGF-like module-containing mucin-like hormone receptor-like 1 & -1.38 & $1.30 \mathrm{E}-05$ & 2015 & - & & & & & & \\
\hline ANXA3 & Annexin A3 & -1.42 & 3.57E-05 & 306 & - & & & & & & \\
\hline TMEM176A & Transmembrane protein $176 \mathrm{~A}$ & -1.29 & 4.95E-05 & 55365 & - & & & & & & \\
\hline CAPG & Macrophage-capping protein & -1.30 & 1.06E-04 & 822 & - & & & & & & \\
\hline DPYSL2 & Dihydropyrimidinase-related protein 2 & -1.38 & $6.02 \mathrm{E}-05$ & 1808 & - & & & & & & \\
\hline IGSF6 & immunoglobulin superfamily, member 6 & -1.31 & $2.52 \mathrm{E}-04$ & 10261 & - & & & & & & \\
\hline IFI6 & Interferon-induced protein 6-16 & -1.32 & $3.05 E-04$ & 2537 & - & & & & & & \\
\hline ADORA3 & Adenosine A3 receptor & -1.34 & 8.81E-04 & 140 & - & & & & & & \\
\hline C1orf115 & Uncharacterized protein C1 orf115. & -1.23 & $2.82 \mathrm{E}-04$ & 79762 & - & & & & & & \\
\hline TRIP10 & Cdc42-interacting protein 4 & -1.20 & $9.05 \mathrm{E}-04$ & 9322 & - & & & & & & \\
\hline FPR1 & fMet-Leu-Phe receptor & -1.22 & 5.83E-04 & 2357 & - & & & & & & \\
\hline TNFRSF8 & Tumor necrosis factor receptor superfamily member 8 & -1.18 & 2.37E-03 & 943 & - & & & & & & \\
\hline GAS2L1 & GAS2-like protein 1 & -1.18 & $1.18 \mathrm{E}-03$ & 10634 & - & & & & & & \\
\hline C1orf163 & Hcp beta-lactamase-like protein C1 orf163. & -1.18 & $1.43 \mathrm{E}-03$ & 65260 & - & & & & & & \\
\hline
\end{tabular}

Figure 4

Genes changed more than $10 \%$ in all individuals after incubation with WY 14,643 . Heat map of genes changed more than $10 \%$ in all individuals after incubation with WY|4,643. Red indicates up-regulation and green indicates down-regulation. SLR, signal log ratio; PPRE, peroxisome proliferator response element 


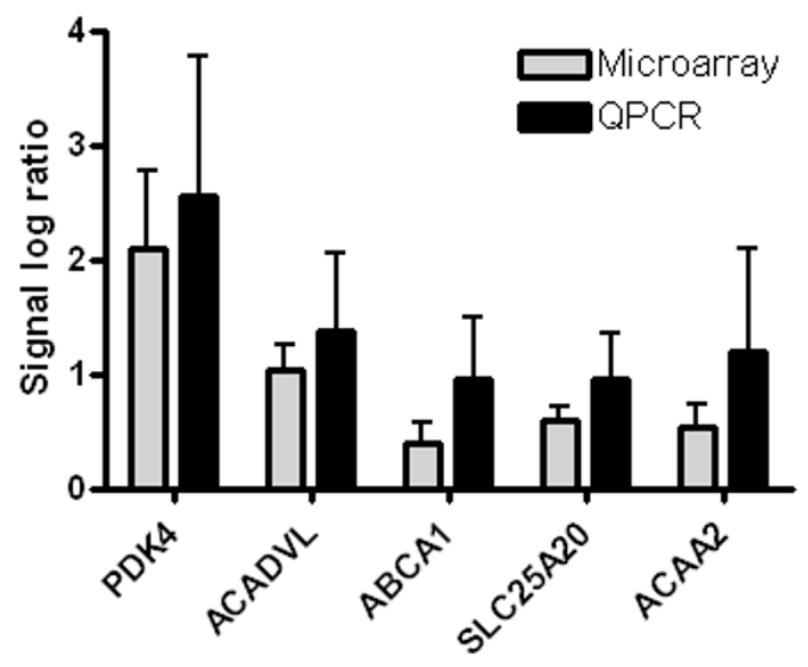

Figure 5

Comparison of microarray and quantitative real time PCR analysis. Mean gene expression changes of microarray and quantitative real time PCR analysis (Q-PCR) of six genes after incubation with WY 14,643. Error bars indicated standard deviations. PDK4, Pyruvate dehydrogenase kinase 4; ACADVL, acyl-Coenzyme A dehydrogenase, very long chain ; ABCA I, ATP binding cassette transporter I; SLC25A20, carnitineacylcarnitine translocase; ACAA2, acetyl-Coenzyme $A$ acyltransferase 2.

of the PPAR $\alpha$ promoter or its target genes may have caused between-subject differences in gene expression levels. Additional studies are required to elucidate whether gene expression profiles can be clustered in different response profiles, simplifying the identification of factors responsible for these individual responses. With respect to personalized nutrition these individual responses are of great interest as it can be expected that nutrients such as fatty acids can induce similar variations in response as WY14,643, which in the end might lead to personalized dietary advice.

The PPRE analyzes of the genes changed showed that approximately $8 \%$ of the genes changed after incubation with the PPAR $\alpha$ ligand WY14,643 contained a predicted or reported PPRE, using the list as described by Lemay et al [15]. However, Lemay et al. report that they tolerate a low false-positive, and a high (60\%) false-negative rate, suggesting that their list of PPREs is far from complete. Our additional transcription factor binding site analysis increase the number of genes that contain a PPRE to a total of $17 \%$ of the genes changed. A network search showed that, besides PPAR, five other transcription factors were involved in direct regulation of at least 10 out of the 1,373 changed genes. Interestingly, all these transcription factors are known to be affected by PPAR $\alpha$ activation [22-

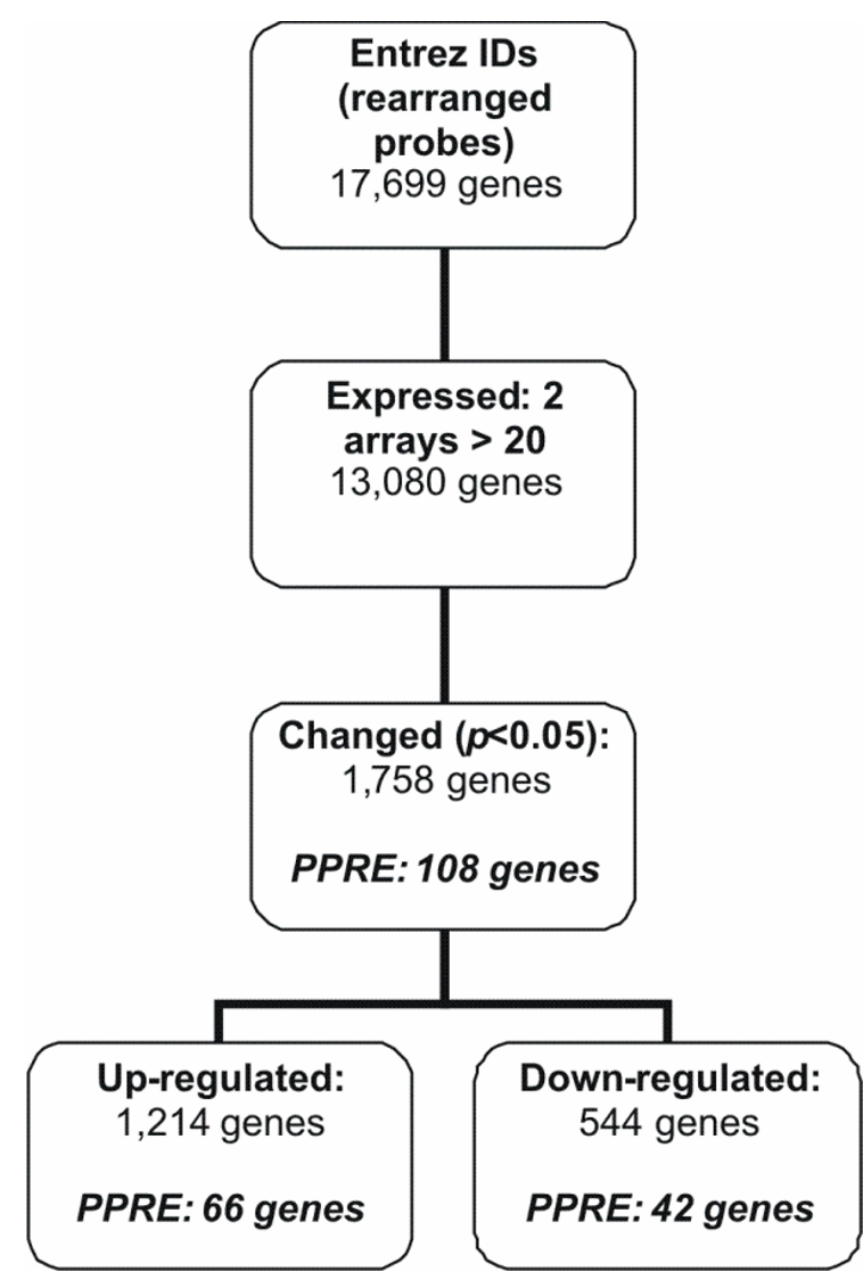

Figure 6

Gene selection procedure after microarray analysis of PBMC of three $\mathbf{2 4}$ hour fasted subjects. Flow chart of the followed gene selection procedure after microarray analysis of PBMC of three 24 hour fasted subjects. PPRE; number of genes containing a peroxisome proliferator response element according to Lemay et al. Data from this fasting study was published previously [14], but has been used here after applying a different annotation procedure.

26]. Transcription factor binding site analysis revealed that, out of the changed genes that did not contain a PPRE, 27\% contained a binding site for at least one of the other five selected transcription factors These genes appear not to be regulated by PPAR $\alpha$ directly, but indirectly, via these other transcription factors, a mechanism which has been suggested before $[27,28]$. The role of PPAR $\alpha$ in this respect seems to be extensively larger than expected based on the outcome of PPRE analyzes alone.

An interesting observation is the decrease in expression level of genes containing a PPRE. Activation of PPAR $\alpha$ by a ligand may result in a negative regulation of genes by 


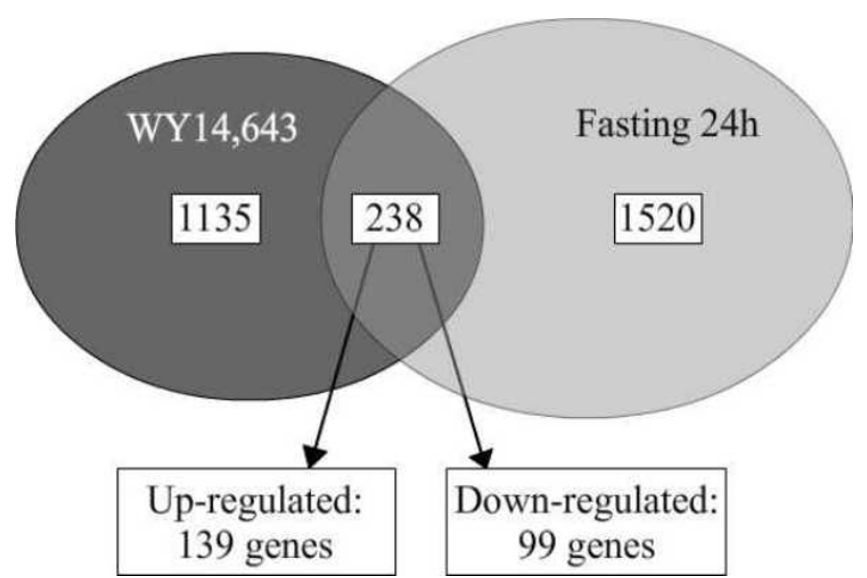

Figure 7

Overlap between genes changed upon WY I4,643 incubation and after $\mathbf{2 4}$ hours fasting. Venn diagram of overlap between genes changed upon WY 14,643 incubation and after 24 hours fasting.

means of transrepression as has been reported in several studies and reviewed by Ricote and Glass (2007) [29]. This transrepression, however, does not require the presence of PPREs in the promoter regions of the target genes. Apparently, negative regulation of these genes, regardless of its mechanism, is stronger than the transcriptional activation of PPAR $\alpha$. Previously, Degenhardt et al. (2006) also showed down regulation of an insulin-like growth factor-binding protein gene (IGFBP-6) that contained a predicted PPRE, in response to the presence of a PPAR $\alpha$ ligand

[30].

The overlap in gene expression profiles between fasting and incubation with WY14,643 shows that PPAR $\alpha$ in PBMCs carries out a substantial part of its function during fasting, when concentrations of its natural ligands, free fatty acids, are elevated in the blood. The main role of PPAR $\alpha$ in PBMCs during fasting is fatty acid $\beta$-oxidation, most likely to cope with the reduced availability of glucose for utilization in energy production and the increase of fatty acids.

Direct comparison between the two array analysis should be examined with care, since the two studies are distinctly different in set-up. The fasting intervention study was conducted in vivo, while the WY14,643 incubation experiments were performed ex vivo. Moreover, fasting involves many more changes in physiology, apart from the beforementioned increase in plasma free fatty acids, including changes in plasma insulin, glucose and leptin concentrations. The PPAR $\alpha$ ligand incubations were set-up to elucidate the specific effects of activation of one nuclear factor, controlling for all other parameters.
Summarizing, this study gives us valuable information on the extent of the effect of PPAR $\alpha$ activation, during fasting and in general, on human PBMC gene expression. It also shows that persons respond differently to PPAR $\alpha$ activation with respect to their gene expression changes, indicating a possible person-specific nutrient response. It seems justified to conclude that human PBMCs are a suitable model to study changes in PPAR $\alpha$ activation. This opens up the possibilities for more specific PPAR $\alpha$ signaling studies in healthy humans using these relatively easily obtainable blood cells.

\section{Methods \\ PBMC incubation}

PBMCs from six healthy Caucasian male blood donors, aged between 30 and $48 \mathrm{yr}$, were isolated directly after arrival of the buffy coat (max. 8 hours after donation) by Ficol-paque Plus density gradient centrifugation (Amersham Biosciences, Roosendaal, the Netherlands). PBMCs were incubated in RPMI1640 medium with $2 \mathrm{mmol} / \mathrm{L} \mathrm{L}$ glutamine, $10 \%$ fetal bovine serum and antibiotics (penicillin and streptomycin) in the presence of $5 \% \mathrm{CO}_{2}$ at $37^{\circ} \mathrm{C}$. at $1.0 \times 10^{6}$ cells per $\mathrm{ml}$ with either WY14,643 (50 $\mu \mathrm{M}$ ) or vehicle (DMSO, $0.1 \%$ ) for 12 hours. All donors gave full written informed consent.

\section{Pre- vs. postprandial incubation}

PBMCs of four healthy volunteers, aged between 28 and 34 , were isolated after a meal and after an overnight fast. PBMCs were incubated at $1.0 \times 10^{6}$ cells per ml with either WY14,643 $(50 \mu \mathrm{M})$ or vehicle (DMSO, 0.1\%) for 12 hours. All volunteers gave full written informed consent.

\section{Statistical methods}

A 2-tailed paired $t$ test was used to determine significant differences in Q-PCR gene expression values between the postprandial and the fasted state. Statistical significance was accepted at $p 0.05$. All calculations were performed with the use of the SPSS (version 12.0.1; SPSS, Chicago, IL).

\section{Microarray processing}

For 6 donors of the incubation experiments, total RNA from PBMCs was labeled using a one-cycle cDNA labeling kit (Affymetrix Inc, Santa Clara, CA) and hybridized to Affymetrix Human whole genome U133 plus 2.0 arrays (Affymetrix). Sample labeling, hybridization to chips and image scanning was performed according to the manufacturer's GeneChip Expression Analysis Technical Manual (Affymetrix).

\section{Intervention study}

For comparison of microarray data of the abovementioned incubation study, with microarray data of PBMC of fasted volunteers, we used the earlier described microarray 
data of a 48 hours fasting study [14]. Briefly, four healthy male Caucasian volunteers, between 19 and 22 year of age were fasted for 48 hours. PBMCs were isolated out of blood taken at baseline, after 24 hours and after 48 hours of fasting. All volunteers gave full written informed consent and the study protocol was approved by the medical ethics committee of Wageningen University.

\section{Microarray analysis}

Microarrays were analyzed using the reorganized oligonucleotide probes as described by Dai et al (2005) [31]. Dai et al. combined all individual probes for a gene, enabling the possibility to detect the overall transcription activity of a gene, based on the latest genome and transcriptome information, instead of the Affymetrix probe set annotation. Application of this annotation procedure on the previously published data from the 48 hours fasting study [14] resulted in a difference in number of genes expressed and changed as compared to the previously used annotation method as this analysis was performed on probe set level.

Expression values were calculated using the Robust Multichip Average (RMA) method. RMA signal value estimates are based on a robust average of background corrected perfect match intensities and normalization was performed using quantile normalization [32,33]. Only genes with normalized signals higher then 20 on at least two out of twelve arrays were defined as expressed and selected for further analysis. Genes were defined as 'changed' when comparison of the normalized signal intensities showed a $\mathrm{p}$-value lower then 0.05 in a two-tailed paired t test with Bayesian correction (Limma) [34]. Pathway analysis was performed using Ingenuity Pathway Analysis 5.5 (Ingenuity Systems). Array data have been submitted to the Gene Expression Omnibus, accession number GSE11289.

\section{PPRE incidence}

To indicated which of the genes changed upon activation of PPAR $\alpha$ had a predicted or reported peroxisome proliferator response element (PPRE), we used information from Lemay et al. [15]. This paper recently reported predicted PPRE on a genome wide scale, using computational genomics and also summarized known PPRE. Using Genomatix software [35], network analysis was performed on 1,373 genes in BiblioSphere, from which transcription factors were selected that were directly linked to more than 10 genes from our list of changed genes. Subsequent transcription factor binding site analysis identified transcription factor binding sites in the promoters of our genes of interest that were cocited at least once in an abstract with these transcription factors. Heat maps were created by using Spotfire software.

\section{cDNA synthesis and quantitative real-time $P C R$}

RNA was reverse transcribed with the use of the cDNA synthesis kit (Promega, Leiden, the Netherlands). Standard quantitative real-time polymerase chain reaction (Q-PCR) was performed with the use of Platinum Taq DNA polymerase and SYBR Green on an iCycler PCR machine (Bio-Rad Laboratories BV) and duplicated at least twice. Primer sequences used in the PCRs were chosen based on the sequences available in PRIMERBANK [36]. Q-PCR data were normalized by measuring cycle threshold ratios between candidate genes and a housekeeping gene, human acidic ribosomal phosphoprotein $\mathrm{PO}$, which was shown to be consistent within PBMCs [37].

\section{Authors' contributions}

$\mathrm{MB}$ collected and analyzed the data and wrote the manuscript. LAA an MM participated in critical revising of the manuscript. None of the authors has a personal or financial conflict of interest.

\section{Additional material}

\section{Additional file 1}

Transcription factor binding site analysis. Presence of transcription factor binding sites in the genes changed in PBMC after incubation with WY14,643. Transcription factors were selected if they directly affected at least 10 genes that were changed after WY14,643 incubation, in a network search using BiblioSphere (Genomatix). FC, fold change; PPRE (Lemay), peroxisome proliferator response element according to Lemay et al. [15]; NFkB, Nuclear factor kappa B binding site; JUN, Jun oncogene binding site; TP53, Tumor protein 53 binding site; SP1, Specificity protein 1 binding site; CTNNB1, catenin beta 1 binding site. Red indicates up regulated, green indicates down regulated

Click here for file

[http://www.biomedcentral.com/content/supplementary/14712164-9-262-S1.pdf]

\section{Acknowledgements}

The authors would like to thank Mechteld Grootte Bromhaar for conducting the microarray processing. This study was supported by the Dutch Dairy Association (Zoetermeer, The Netherlands).

\section{References}

I. Issemann I, Green S: Activation of a member of the steroid hormone receptor superfamily by peroxisome proliferators. Nature 1990, 347(6294):645-650.

2. Gottlicher M, Widmark E, Li Q, Gustafsson JA: Fatty acids activate a chimera of the clofibric acid-activated receptor and the glucocorticoid receptor. Proc Natl Acad Sci U S A 1992, 89(10):4653-4657.

3. Keller H, Dreyer C, Medin J, Mahfoudi A, Ozato K, Wahli W: Fatty acids and retinoids control lipid metabolism through activation of peroxisome proliferator-activated receptor-retinoid X receptor heterodimers. Proc Natl Acad Sci U S A 1993, 90(6):2160-2164

4. Kersten S, Wahli W: Peroxisome proliferator activated receptor agonists. Exs 2000, 89:|4|-|5|.

5. Sanderson LM, De Groot PJ, Hooiveld GJ, Koppen A, Kalkhoven E, Müller M, Kersten S: Effect of Synthetic Dietary Triglycerides: 
A Novel Research Paradigm for Nutrigenomics. PLOS ONE 2008, 3(2): el68I.

6. Mandard S, Muller M, Kersten S: Peroxisome proliferator-activated receptor alpha target genes. Cell Mol Life Sci 2004, 6I(4):393-4I6.

7. Kersten S, Mandard S, Escher P, Gonzalez FJ, Tafuri S, Desvergne B, Wahli W: The peroxisome proliferator-activated receptor alpha regulates amino acid metabolism. Faseb J 200I, I 5(II): I97I-I 978.

8. Kostadinova R, Wahli W, Michalik L: PPARs in diseases: control mechanisms of inflammation. Curr Med Chem 2005, I 2(25):2995-3009.

9. Stienstra R, Duval C, M ML, Kersten S: PPARs, Obesity, and Inflammation. PPAR Res 2006, 2007:95974.

10. Marx N, Kehrle B, Kohlhammer K, Grub M, Koenig W, Hombach V, Libby P, Plutzky J: PPAR activators as antiinflammatory mediators in human $T$ lymphocytes: implications for atherosclerosis and transplantation-associated arteriosclerosis. Circ Res 2002, 90(6):703-7I0.

II. Chinetti G, Griglio S, Antonucci M, Torra IP, Delerive P, Majd Z, Fruchart JC, Chapman J, Najib J, Staels B: Activation of proliferatoractivated receptors alpha and gamma induces apoptosis of human monocyte-derived macrophages. J Biol Chem 1998, 273(40):25573-25580.

12. Maas K, Chan S, Parker J, Slater A, Moore J, Olsen N, Aune TM: Cutting edge: molecular portrait of human autoimmune disease. J Immunol 2002, 169(I):5-9.

13. Burczynski ME, Dorner A]: Transcriptional profiling of peripheral blood cells in clinical pharmacogenomic studies. Pharmacogenomics 2006, 7(2): 187-202.

14. Bouwens M, Afman LA, Muller M: Fasting induces changes in peripheral blood mononuclear cell gene expression profiles related to increases in fatty acid \{beta\}-oxidation: functional role of peroxisome proliferator activated receptor $\{$ alpha\} in human peripheral blood mononuclear cells. Am J Clin Nutr 2007, 86(5): $1515-1523$.

15. Lemay DG, Hwang DH: Genome-wide identification of peroxisome proliferator response elements using integrated computational genomics. J Lipid Res 2006, 47(7): I583-I587.

16. Kersten S, Seydoux J, Peters JM, Gonzalez FJ, Desvergne B, Wahli W: Peroxisome proliferator-activated receptor alpha mediates the adaptive response to fasting. I Clin Invest 1999, I 03(I I): I 489-I 498

17. Bunger M, van den Bosch HM, van der Meijde J, Kersten S, Hooiveld G], Muller M: Genome-wide analysis of PPARalpha activation in murine small intestine. Physiol Genomics 2007, 30(2): 192-204.

18. Swagell CD, Henly DC, Morris CP: Regulation of human hepatocyte gene expression by fatty acids. Biochem Biophys Res Commun 2007, 362(2):374-380.

19. Tachibana K, Anzai N, Ueda C, Katayama T, Kirino T, Takahashi R, Yamasaki D, Ishimoto K, Tanaka T, Hamakubo T, Ueda $Y$, Arai $H$, Sakai J, Kodama T, Doi T: Analysis of PPAR alpha function in human kidney cell line using siRNA. Nucleic Acids Symp Ser (Oxf) 2006:257-258.

20. Beck GC, Rafat N, Brinkkoetter P, Hanusch C, Schulte J, Haak M, van Ackern $\mathrm{K}$, van der Woude FJ, Yard BA: Heterogeneity in lipopolysaccharide responsiveness of endothelial cells identified by gene expression profiling: role of transcription factors. Clin Exp Immunol 2006, I 43(3):523-533.

21. Martin-Fuentes P, Civeira F, Recalde D, Garcia-Otin AL, Jarauta E, Marzo I, Cenarro A: Individual variation of scavenger receptor expression in human macrophages with oxidized low-density lipoprotein is associated with a differential inflammatory response. J Immunol 2007, 179(5):3242-3248.

22. Genolet R, Wahli W, Michalik L: PPARs as drug targets to modulate inflammatory responses? Curr Drug Targets Inflamm Allergy 2004, 3(4):36I-375

23. Irukayama-Tomobe $\mathrm{Y}$, Miyauchi T, Sakai S, Kasuya $\mathrm{Y}$, Ogata T, Takanashi M, lemitsu M, Sudo T, Goto K, Yamaguchi I: Endothelin-Iinduced cardiac hypertrophy is inhibited by activation of peroxisome proliferator-activated receptor-alpha partly via blockade of c-Jun NH2-terminal kinase pathway. Circulation 2004, 109(7):904-910.

24. Morimura K, Cheung C, Ward JM, Reddy JK, Gonzalez FJ: Differential susceptibility of mice humanized for peroxisome prolif- erator-activated receptor alpha to $\mathbf{W y}-14,643$-induced liver tumorigenesis. Carcinogenesis 2006, 27(5): 1074-1080.

25. Krey G, Mahfoudi A, Wahli W: Functional interactions of peroxisome proliferator-activated receptor, retinoid-X receptor, and $\mathrm{Spl}$ in the transcriptional regulation of the acyl-coenzyme-A oxidase promoter. Mol Endocrinol 1995, 9(2):219-23I.

26. Santos MJ, Quintanilla RA, Toro A, Grandy R, Dinamarca MC, Godoy JA, Inestrosa NC: Peroxisomal proliferation protects from beta-amyloid neurodegeneration. J Biol Chem 2005, 280(49):41057-41068.

27. Yang Q, Gonzalez FJ: Peroxisome proliferator-activated receptor alpha regulates $B$ lymphocyte development via an indirect pathway in mice. Biochem Pharmacol 2004, 68(II):2143-2I50.

28. Xie $Y$, Yang Q, DePierre JW: The effects of peroxisome proliferators on global lipid homeostasis and the possible significance of these effects to other responses to these xenobiotics: an hypothesis. Ann N Y Acad Sci 2002, 973:17-25.

29. Ricote $M$, Glass CK: PPARs and molecular mechanisms of transrepression. Biochim Biophys Acta 2007, I77 I(8):926-935.

30. Degenhardt T, Matilainen M, Herzig KH, Dunlop TW, Carlberg C: The insulin-like growth factor-binding protein I gene is a primary target of peroxisome proliferator-activated receptors. J Biol Chem 2006, 28 I(5 I):39607-396I9.

31. Dai M, Wang P, Boyd AD, Kostov G, Athey B, Jones EG, Bunney WE, Myers RM, Speed TP, Akil H, Watson SJ, Meng F: Evolving gene/ transcript definitions significantly alter the interpretation of GeneChip data. Nucleic Acids Res 2005, 33(20):e 175.

32. Irizarry RA, Bolstad BM, Collin F, Cope LM, Hobbs B, Speed TP. Summaries of Affymetrix GeneChip probe level data. Nucleic Acids Res 2003, 3 I(4): el5.

33. Bolstad BM, Irizarry RA, Astrand M, Speed TP: A comparison of normalization methods for high density oligonucleotide array data based on variance and bias. Bioinformatics 2003 , 19(2): 185-193.

34. Smyth GK: Linear models and empirical bayes methods for assessing differential expression in microarray experiments. Stat Appl Genet Mol Biol 2004, 3:Article3.

35. Genomatix Software GmbH [http://www.genomatix.de/prod ucts/BiblioSphere/]

36. PRIMERBANK [http://pga.mgh.harvard.edu/primerbank/ index.html]

37. Dheda K, Huggett JF, Bustin SA, Johnson MA, Rook G, Zumla A: Validation of housekeeping genes for normalizing RNA expression in real-time PCR. Biotechniques 2004, 37(1): I | 2-4, I | 6, I I89.

Publish with BioMed Central and every scientist can read your work free of charge

"BioMed Central will be the most significant development for disseminating the results of biomedical research in our lifetime."

Sir Paul Nurse, Cancer Research UK

Your research papers will be:

- available free of charge to the entire biomedical community

- peer reviewed and published immediately upon acceptance

- cited in PubMed and archived on PubMed Central

- yours - you keep the copyright 